Relations industrielles

Industrial Relations

\title{
La marche sur Québec
}

\section{André Raynauld}

Volume 12, numéro 4, octobre 1957

URI : https://id.erudit.org/iderudit/1022516ar

DOI : https://doi.org/10.7202/1022516ar

Aller au sommaire du numéro

Éditeur(s)

Département des relations industrielles de l'Université Laval

ISSN

0034-379X (imprimé)

1703-8138 (numérique)

Découvrir la revue

Citer ce document

Raynauld, A. (1957). La marche sur Québec. Relations industrielles / Industrial Relations, 12(4), 383-384. https://doi.org/10.7202/1022516ar

Tous droits réservés @ Département des relations industrielles de l’Université Laval, 1957
Ce document est protégé par la loi sur le droit d'auteur. L'utilisation des services d'Érudit (y compris la reproduction) est assujettie à sa politique d'utilisation que vous pouvez consulter en ligne.

https://apropos.erudit.org/fr/usagers/politique-dutilisation/ 
de la Confédération des Travailleurs Catholiques trouveront sans doute dans le conflit en cours de nouveaux motifs de resserrer les liens qui les rattachent et, qui sait, d'amener tous les travailleurs du Québec au sein d'un seul mouvement désormais unifié.

En plus d'affirmer la solidarité ouvrière, la marche sur Murdochville souligne les effets profonds de l'industrialisation dans les centres ruraux. Depuis les dernières années, nombre de territoires économiquement déprimés ont vu leur grand surplus de travailleurs s'adonner en nombre toujours croissant à des emplois salariés, trouvant leur subsistance dans les forêts ou dans les centres environnants.

Tout comme le travailleur de la ville, le salarié de la campagne en vient a dépendre presque uniquement de son salaire. Il ne peut plus, comme ses parents ou grands-parents, compter que le sol le fera vivre de façon substantielle. Il ne faut donc pas s'étonner de la rapidité avec laquelle le syndicalisme peut s'implanter dans les centres ruraux où existe une forte capitalisation dans l'exploitation des ressources naturelles. Si le syndicalisme n'y remporte pas le même succès que dans les villes, il faut moins s'en prendre à l'individualisme des travailleurs ruraux qu'au fait que le syndicalisme doit y faire face à de puissants obstacles. Entre le travailleur syndiqué de la ville et celui de la campagne, les différences sur le plan des motivations sont mince. Aussi, les travailleurs du Québec allant prêter leur concours aux grévistes de Murdochville n'allaient pas visiter des agriculteurs momentanément en difficulté avec un employeur d'occasion, mais il s'agissait d'ouvriers se portant à l'aide d'autres ouvriers, et parlant le même langage.

Le phénomène d'industrialisation est irréversible, même dans les centres ruraux. Partout où se rencontrent des personnes vivant principalement de salaires, il faut s'attendre à voir naître chez les travailleurs les mêmes aspirations vers l'organisation professionnelle. Des difficultés momentanées peuvent ralentir la marche vers l'organisation syndicale, mais dans les pays démocratiques l'histoire a déjà prouvé depuis des siècles que les travailleurs réussissent toujours, après des délais plus ou moins considérables, à faire reconnaître leur syndicat par lemployeur, les gouvernants et le public.

(Causerie prononcée à Radio-Canada le 20 août 1957.)

\section{La marche sur Québec}

\section{André Raynauld}

La marche sur Québec que la Confédération des Travailleurs Catholiques du Canada et la Fédération des Travailleurs du Québec entreprennent est très lourde de signification.

Cette marche est d'abord une manifestation de sympathie et de solidarité de la part des représentants de tous les travailleurs organisés envers leurs confrères de la Gaspe Copper Mines, en grève depuis les six derniers mois.

C'est ensuite une tentative nouvelle des syndicats pour éveiller l'opinion publique à ce qui paraît devenir un scandale politique, dans le domaine des relations ouvrières, plus grave encore que celui d'Asbestos. Un tel recours à l'opinion publique est généralement le signe non équivoque d'une situation désespérée. Les travailleurs l'utilisent quand ils ont épuisé les méthodes juridiques ou que celles-ci sont utilisées d'une manière telle qu'elles ne laissent aucun espoir de solution rapide et définitive. C'est bien le cas actuel de Murdochville. Comme l'article que le Révérend Père Cousineau a publié dans la revue Relations le démontre précisément et vigoureusement, les travailleurs ne peuvent espérer de la part des tribunaux aucun redressement à leur situation avant plusieurs années. La raison en est fort simple. La Gaspe Copper Mines a obtenu un bref de prohibition contre la Commission de Relations Ouvrières, ce qui empêche celle-ci d'accorder un certificat de reconnais- 
sance au syndicat qui représente actuellement les travailleurs. Le syndicat par suite est incapable, juridiquement, de forcer l'employeur à négocier une convention collective avec lui. Le bref, évidemment, peut être renvoyé par les tribunaux compétents. Mais lorsqu'une Cour de première instance l'aura fait, rien n'empêchera la compagnie de recourir à un tribunal supérieur, de recourir même à la Cour Suprême, vraisemblablement, puisque la Loi des relations ouvrières elle-même est mise en question.

Sans doute dira-t-on, les syndicats ouvriers n'ont pas épuisé les procédures juridiques, puisque leur grève est illégale depuis le début. Sans doute la grève est-elle illégale. Mais comment peut-il en être autrement quand, pour être légale, la grève suppose que l'autre partie reconnaisse au moins l'agent négociateur. Ce que la Gaspe Copper Mines n'a jamais fait puisqu'elle conteste la légalité des pouvoirs de la Commission de Relations Ouvrières.

Les gouvernements peuvent aussi intervenir en marge des tribunaux. Dans le cas de Murdochville, le gouvernement fédéral s'est récusé en alléguant les limites de sa juridiction, ce qui nous parait juridiquement fondé. Le gouvernement provincial a aussi refusé d'intervenir sous le fallacieux prétexte que les esprits sont trop échauffés pour qu'une intervention soit utile. Comme s'il fallait que le gouvernement n'intervienne que lorsque le conflit est déjà résolu!

Que reste-t-il aux syndicats sinon l'opinion publique, sinon la conscience publique des injustices qui sont commises au nom de la loi et dans l'indifférence des autorités responsables du respect de la justice.

La marche sur Québec est enfin et surtout une marche dont l'objectif essentiel est de faire respecter le droit d'association pour les travailleurs. Ce droit est violé actuellement par la Gaspe Copper Mines, une compagnie étrangère dont les opérations se font sur un territoire de la Couronne moyennant un permis gouvernemental d'exploitation. On peut se permettre de dire que ce droit des travailleurs est violé parce que le bref de la Compagnie a obtenu contre la Commission de Relations ouvrières prive le syndicat de tout pouvoir légal et coercitif de négociation, et parce qu'en plus la Compagnie refuse de reconnaître et de négocier de bonne foi avec un syndicat qui représente tellement adéquatement les travailleurs de l'endroit que ceux-ci sont encore en grève après six mois de lutte.

Or le droit d'association est un droit fondamental des travailleurs, un droit reconnu ouvertement par l'Eglise, un droit reconnu par la loi dans tous les pays occidentaux et cela depuis au moins un siècle en certains pays.

La marche sur Québec poursuivant ainsi un objectif fondamental et qui apparaît clairement comme tel aux yeux de tous, la marche sur Québec étant d'autre part un recours de dernière instance pour ceux qui l'entreprennent, il serait extrêmement dangereux pour la société québecoise que cette marche ne donne aucun résultat ou qu'elle ne soulève aucun écho profond dans la masse de la population. A certaines époques, dit Bernanos, il faut une explosion de la raison, sinon on s'achemine dans les pires désordres. Il faut éviter à tout prix que les travailleurs ne croient à l'irréparable, car alors il est à craindre qu'ils ne prennent des moyens moins démocratiques de faire reconnaître leurs droits. Que l'explosion de la raison éclate, sinon c'est l'explosion de la colère que nous risquons de rencontrer sur notre route.

(Causerie prononcée à Radio-Canada, 13 septembre 1957.) 